\title{
EDITORIAL
}

\section{THE INCLUSION OF MATHEMATICS TO THE SRI LANKAN MEDICAL CURRICULUM}

\section{Edussuriya D.H}

Department of Forensic Medicine, Faculty of Medicine, University of Peradeniya, Sri Lanka

Numeracy and literacy are considered two of the most important skills for medical practitioners. Even though the Sri Lankan medical curricular provide opportunities for students to improve their literacy skills through short courses conducted by the faculties, there seems to be no move towards improving their numeracy skills.

Researchers hypothesize that some medical students experience 'numerophobia' - a perceived and disproportionate fear of numbers and simple mathematical manipulation. ${ }^{1}$ In the Sri Lankan context this maybe compounded by the fact that mathematics is not a requirement to follow the medical program.

Mathematics is possibly the ideal training for any career in science, medicine, law, or business and would contribute to a well-rounded education. ${ }^{2}$ Universities world-wide which consider mathematics as a prerequisite for the medical course justify its requirement in many ways. Even though some consider it a "weeding tool", to select those students who have high cognitive ability, some universities make following a course in mathematics compulsory after selection to the medical course in order to develop their reasoning and analytical skills. $^{3}$

Inclusion of mathematics into the Sri Lankan medical curriculum could be justified not only by the fact that a mathematics knowledge is needed to; calculate drug doses, concentrations, calculate acid-base status and understand the core statistical concepts most commonly represented in the medical literature ${ }^{4}$ but by also considering the fact that a mathematics training for medical students would teach rigorous thought and logical reasoning that are needed for clinical reasoning, ${ }^{5}$ facilitate problem solving, probabilistic reasoning and creativity and provide the ability and confidence to conduct high quality research, review of articles and encourage the practice of evidence-based medicine. 


\section{REFERENCES}

1. Ben-Shlomo Y, Fallon U, Sterne J, Brookes S. Do medical students with A-level mathematics have a better understanding of the principles behind evidence-based medicine?. Medical teacher. 2004 Dec 1;26 (8):731-3.

2. Jeff Anderson. We use Math org [Internet]. America: American Mathematical Society; 2017 [cited $2018 \mathrm{Jul}$ 03]. Available from: http://weusemath.byu.edu/career/physician

3. Prerequisites and Requirements. The Johns Hopkins University [cited 2018 Jul 03]. Available from:

http://www.hopkinsmedicine.org/som/admis sions/md/application_process/prerequisites_ requirements

4. Nusbaum NJ. PERSPECTIVES: Mathematics Preparation for Medical School: Do All Premedical Students Need Calculus?. Teaching and learning in medicine. 2006 Apr 1;18(2):165-8.

5. Benner P, Hughes RG, Sutphen M. Patient Safety and Quality: An Evidence-Based Handbook for Nurses [cited 2018 Jul 03]. Available from:

https://www.ncbi.nlm.nih.gov/books/ NBK2643/ 